\title{
Peer-led education or booklet for knowledge transfer about disease: A randomized-controlled trial with ankylosing spondylitis patients
}

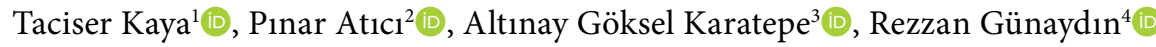 \\ ${ }^{1}$ Department of Physical Medicine and Rehabilitation, Izmir Bozyaka Training and Research Hospital, Izmir, Turkey \\ ${ }^{2}$ Department of Physical Medicine and Rehabilitation, Nevşehir State Hospital, Nevşehir, Turkey \\ ${ }^{3}$ Department of Physical Medicine and Rehabilitation, Izmir Bozyaka Training and Research Hospital, Izmir, Turkey \\ ${ }^{4}$ Department of Physical Medicine and Rehabilitation, Medical Park Izmir Hospital, Izmir, Turkey
}

\begin{abstract}
Objectives: This study aims to investigate whether peer-led group education + booklet is superior to booklet only to increase ankylosing spondylitis (AS) patients' knowledge about their disease.

Patients and methods: A total of 56 patients ( 46 males, 10 females; mean age $41.9 \pm 9.2$ years; range, 22 to 58 years) with a definite diagnosis of AS who were under follow-up in our outpatient clinic between August 2010 and January 2012 were included in this study. The patients were randomly allocated to the peer-led education + booklet (education group, $n=27$ ) and booklet only (control group, $n=29$ ). To assess the level of patients knowledge, a patient knowledge questionnaire containing four domains was used. Evaluations were made at baseline, four weeks, and six months. The variables were "number of correct choices" (NoCC), "number of correct items" (NoCl) and percent of correct choices for each domain; the later one was resembled by the name of that domain (area A, area B, etc.).

Results: The variables that improved in both groups were NoCC, NoCl, and "pharmacotherapy and physical therapy area" (area C). These improvements were similar between the groups (respectively, $p=0.915, p=0.830, p=0.791$ ).

Conclusion: Reading a booklet alone is as successful as peer-led education + booklet for knowledge transfer about their disease in patients with AS In this study, the most knowledge gain was achieved in "drug treatment and physical therapy" area.

Keywords: Ankylosing spondylitis, knowledge, patient education.
\end{abstract}

Effective management of patients with chronic diseases is considered to be possible only, when patients are informed about their care. ${ }^{1}$ Patient education is considered a way of enhancing compliance with treatment and improving health status by increasing the knowledge about disease..$^{1-8}$ For patients with chronic diseases, improvement in health status depends upon the collaboration between patients and healthcare professionals. This collaboration is possible as long as the patients know more about their disease and its treatment. According to the results of several studies, improved knowledge level about disease is expected to allow patients to involve in the management of their disease. In this context, patient education and successful knowledge transfer is accepted as a crucial component of healthcare efforts. First of all, improved knowledge level about disease and its treatment is essential to avoid mistaken health-related behaviors. ${ }^{9}$ This is

Received: July 09, 2020 Accepted: March 06, 2021 Published online: October 16, 2021

Correspondence: Taciser Kaya, MD. İzmir Bozyaka Eğitim ve Araştırma Hastanesi Fiziksel Tıp ve Rehabilitasyon Kliniği, 35170 Karabağlar, İzmir, Türkiye. Tel: +90 532 - 3948990 e-mail: taciserkaya@gmail.com

\section{Citation:}

Kaya T, Atıcı P, Göksel Karatepe A, Günaydın R. Peer-led education or booklet for knowledge transfer about disease: A randomized-controlled trial with ankylosing spondylitis patients. Arch Rheumatol 2021;36(4):560-569. 
particularly important for patients with chronic diseases such as ankylosing spondylitis (AS). For this purpose, several types of educational interventions such as professional-led groups, lay-led groups, individual teaching, home study and passive technics (booklets, audio-visual programs) have been developed and used to date along with management of patients with inflammatory arthritis.,4,10-12 However, it is not clear which type of education program is the most optimal method to achieve adequate knowledge transfer. ${ }^{4}$

Ankylosing spondylitis is defined as a noncurable disease requiring long-term management by providing regular exercise performance, developing joint protection skills, and enhancing correct medication use. ${ }^{13}$ Patient education programs are considered essential to obtain these benefits. ${ }^{5}$ For AS patients, Claudepierre et al. ${ }^{6}$ emphasized the importance of reading booklets or contact with patient groups to improve knowledge about disease. There is no consensus on the most suitable tutorial who would serve educational sessions to obtain more gain regarding knowledge of disease. The European League Against Rheumatism (EULAR) has stated trained patients among tutorial alternatives for delivering patient education in patients with inflammatory arthritis. ${ }^{7}$

The peer-led education programs may be generic or disease-specific in nature. ${ }^{14,15}$ There are many articles reporting the results of group education activities for osteoarthritis, rheumatoid arthritis (RA), or mixed group of arthritis participants..$^{3,4,8-10,16-19}$ In a Cochrane review, educational interventions used in clinical trials were mostly generic rather than disease-specific and, based on this finding, the need for diseasespecific interventions for chronic diseases was emphasized. ${ }^{15}$ To the best of our knowledge, clinical trials evaluating benefits of education on AS patients' knowledge level about their disease are scarce in the English literature. There is only one study assessing post-intervention knowledge level. ${ }^{20}$ However, in this study, the sample size is too small ( $\mathrm{n}=11$ with spouses) and the education was not peer-led. Besides these, the follow-up period was only four weeks and the subtopic that most learned was not reported.

Considering this gap, we attempted to initiate a study investigating the impact of peer-led education on the patients' knowledge about their disease. We, therefore, hypothesized that patients with AS might learn about their disease after education delivered by peer-leaders. On the other hand, also reading a booklet is suggested as one of effective way for learning about disease by numerous authors. ${ }^{2,6,10,11}$ Thus, in this study, we aimed to investigate whether peer-led group education + booklet was superior to reading an educational booklet only to increase AS patients' knowledge about their disease.

\section{PATIENTS AND METHODS}

This open-label, randomized-controlled study was conducted at Izmir Bozyaka Training and Research Hospital, Department of Physical Medicine and Rehabilitation between August 2010 and January 2012. Patients with definite AS who were under follow-up in our outpatient clinic were screened. Inclusion criteria were as follows: having a diagnosis of AS for at least one year, age between 18 and 75 years, having not subjected to an education program within the last three years, and being capable of completing the questionnaire. All participants were invited by phone calls in an orderly fashion from the registered patient list. The permuted block randomization list was used to allocate patients to the groups. To avoid patient bias, those who were not willing to participate in education group were not invited to attend to the control group and the next consecutive one in the registered patient list was invited.

A total of 112 patients were reached by telephone. Eighty patients were eligible and included in the study. Of these, 40 were allocated to the education + booklet group and 40 were allocated to the booklet only group. The study flow chart is shown in Figure 1. We conducted a clinical trial to investigate the impact of peer-led group education on perceived health status of patients with AS and reported our findings. ${ }^{21}$ To measure the effect of peer-led education on knowledge gain about their disease, the participants in that study were also tested using a patient knowledge questionnaire. These two studies were approved separately by the Izmir Bozyaka Training and Research Hospital Ethics Committee (Date-no: 01.07.2010-05). All participants were informed 


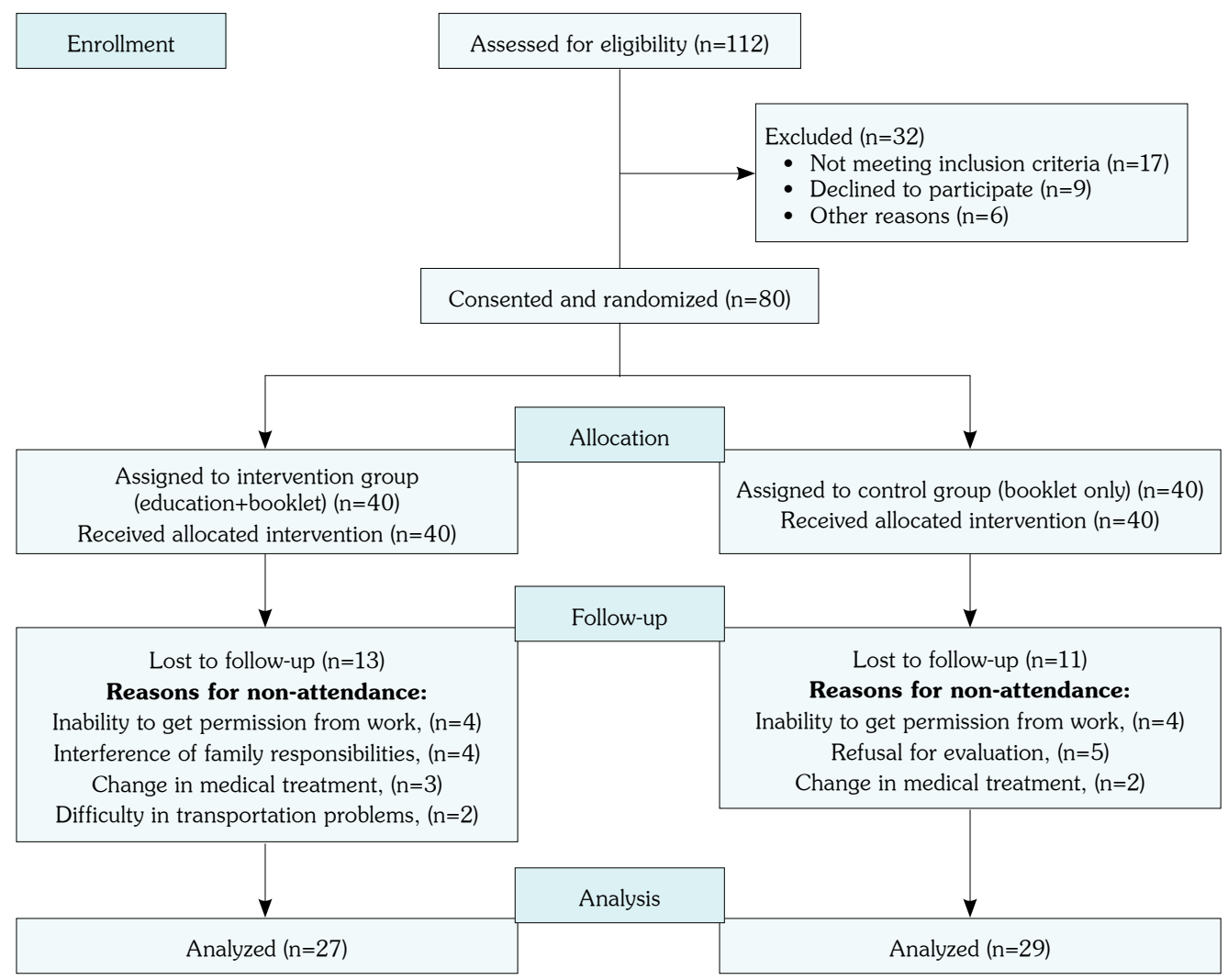

Figure 1. Study flow chart.

about the nature of the study and informed by the consent form about the equal chance of assignment to either education or control group prior to participation. A written informed consent was obtained. The study was conducted in accordance with the principles of the Declaration of Helsinki.

\section{Peer educators and intervention}

At the beginning of the study, four patients from the sample who were followed in our clinic with a diagnosis of AS for at least three years were selected as peer educators. First, they participated in two training sessions by the same physician experienced in the field of rheumatologic diseases. Peer educators were also instructed about the presentation techniques.

The education group was divided into four groups including 10 patients in each. For each group, a four-week education program -one hour weekly- was conducted by peer educators. During sessions, peer educators presented an informative slide show about etiology, clinical findings, complications and treatment of AS, importance of exercise therapy, and joint protection methods.

\section{Measurement of the patients' knowledge about disease}

At baseline, both the education and control group were asked to answer a self-administered questionnaire to assess the level of patients' knowledge about their disease. For this purpose, a patient knowledge questionnaire was used which was developed by Lubrano et al. ${ }^{5}$ This questionnaire covers 14 multiple-choice items and queries patients' knowledge in four following domains: area A, general knowledge, etiology, symptoms and blood tests (questions 1-4); area $\mathrm{B}$, human leukocyte antigen-B27 (HLA-B27) and inheritance (questions 5 and 14); area $\mathrm{C}$, drug treatment and physical therapy (questions $6,7,10,11,13$ ); and area D, joint protection, pacing and priorities (questions 8,9,12). Each item presents one or two true statements. The number of choices is 72 in total of which 25 is correct. ${ }^{5,6}$ 
For detailed information, the questions related to general knowledge (area A) queries whether or not AS is an infectious disease or most common in older age, caused by injury, a curable disease, gets worse in the cold weather, increases the risk of cancer or stroke, etc. In area C, drugs, therapeutic or detrimental effects of water and land-based exercises, fluctuations in symptoms, activities to be avoided, impact of disease on physical activity are queried. The questions in area $\mathrm{D}$ queries correct sleeping position in bed and proper physical activity in acute flare and their benefits. ${ }^{5,6}$

After the initial evaluation, both groups received an educational booklet which developed for this study. The content of booklet was prepared by the authors based on consensus.

The information in the booklet was also constituted the topic of the educational sessions provided to the education group. The control group was not subjected to any intervention. The participants were re-tested after four weeks (immediate after education) and at six months.

\section{Main outcome variables}

The primary outcome of the study was the change in knowledge level after peer-led education.

We intended to measure knowledge gain in total and also in areas which described in the questionnaire separately. Thus, three different types of scores were named, calculated, and recorded for use in statistical analyses:

1. The "number of correct choices" (NoCC): NoCC was calculated by summing the correct choices. Each of the correct choice was assumed as one point (maximum possible 25).

2. The number of correct items (NoCI, maximum possible 14): giving one point to each correct item, assuming an item as correct if it was answered by choosing all of the true statements and none of the false statements.

We defined NoCC and NoCI as "total knowledge scores" overall.

3. We calculated the number and, then, percent of correct choices (not correct items) for each domain. For this calculation, the correct choices of items taking part in a given area were counted and summed, and a score was obtained.
Then, the percentage of correct choices in all choices was calculated and resembled by the name of the domain (area $\mathrm{A}$ or area $\mathrm{B}$, etc.).

\section{Statistical analysis}

Statistical analysis was performed using the SPSS version 15.0 software (SPSS Inc., Chicago, IL, USA). The Shapiro-Wilk test was applied to test the normal distribution. Descriptive data were expressed in mean \pm standard deviation (SD), median (min-max) or number and frequency, where applicable. Differences in baseline characteristics between two study groups were assessed using independent sample t-test, chi-square test, and Mann-Whitney U test, where appropriate. The non-parametric Friedman test was used to detect changes in the scores between three occasions (baseline, Week 4, and Month 6) and proceeded with Wilcoxon signed-rank test, if significant. To compare the groups in respect to changes in the variables, the Mann-Whitney $U$ test was used. A $p$ value of $<0.05$ was considered statistically significant.

\section{RESULTS}

Thirteen patients in the education group and 11 patients in the control group dropped out before completing the study and, therefore, the dropout rates were $32.5 \%$ and $27.5 \%$ for the education and control groups, respectively. Finally, a total of 56 patients (46 males, 10 females; mean age $41.9 \pm 9.2$ years; range, 22 to 58 years) were included in the study. Of the patients, 27 in the education group and 29 in the booklet only group completed the study. Baseline comparisons between the groups indicated no significant differences in sociodemographics and diseaserelated variables (Table 1 ). The patients who completed the educational sessions were not different from non-completers with respect to sociodemographics or baseline clinical variables in either group (data not shown).

\section{Intra-group analysis}

Only NoCC, NoCI, and area C (pharmacotherapy and physical therapy area) scores changed in both groups. In the education group, area A and, in the control group, areas B and D scores remained unchanged (Table 2). 
Table 1. Demographic characteristics of the patients, disease-related variables, and outcome measures

\begin{tabular}{|c|c|c|c|c|c|c|c|c|c|}
\hline & \multicolumn{4}{|c|}{ Education group $(n=27)$} & \multicolumn{4}{|c|}{ Control group $(\mathrm{n}=29)$} & \multirow[b]{2}{*}{$p$} \\
\hline & $\mathrm{n}$ & Mean \pm SD & Median & Min-Max & $\mathrm{n}$ & Mean \pm SD & Median & Min-Max & \\
\hline Age (year)* & & $43.1 \pm 9.1$ & & & & $40.9 \pm 9.3$ & & & 0.961 \\
\hline $\begin{array}{l}\text { Sext } \\
\quad \text { Male } \\
\text { Female }\end{array}$ & $\begin{array}{c}21 \\
6\end{array}$ & & & & $\begin{array}{c}25 \\
4\end{array}$ & & & & 0.411 \\
\hline Marital status (married) $\dagger$ & 19 & & & & 23 & & & & 0.440 \\
\hline Duration of education (year) $\neq$ & & & 7 & $5-19$ & & & 8 & $0-15$ & 0.952 \\
\hline Employed $\dagger$ & 12 & & & & 17 & & & & 0.289 \\
\hline Time from diagnosis (year) $\neq$ & & & 9 & $1-31$ & & & 5 & $1-25$ & 0.186 \\
\hline $\operatorname{BASDAI}(0-10) \neq$ & & & 3.4 & $0.2-9.2$ & & & 2.2 & $0.4-6.7$ & 0.098 \\
\hline BASFI $(0-10) \neq$ & & & 3.9 & $0.3-8.5$ & & & 2.1 & $0.1-7.4$ & 0.523 \\
\hline BASMI $(0-10) \neq$ & & & 4 & $0-10$ & & & 3 & $0-10$ & 0.164 \\
\hline $\operatorname{ESR}(\mathrm{mm} / \mathrm{h}) \neq$ & & & 26 & $1-106$ & & & 20 & $4-59$ & 0.491 \\
\hline $\mathrm{CRP}(\mathrm{mg} / \mathrm{dL}) \neq$ & & & 0.9 & $0.15-5.1$ & & & 0.7 & $0.0-3.2$ & 0.528 \\
\hline NoCC $\neq$ & & & 16 & $9-23$ & & & 15 & $6-22$ & 0.299 \\
\hline NoCl & & & 6 & $2-11$ & & & 6 & $0-12$ & 0.488 \\
\hline Area $A \neq$ & & & 0.75 & $0.25-1$ & & & 0.62 & $0-1$ & 0.187 \\
\hline Area $B \neq$ & & & 0.33 & $0-0.67$ & & & 0.33 & $0-9.67$ & 0.791 \\
\hline Area $\mathrm{C} \neq$ & & & 0.67 & $0.33-1$ & & & 0.67 & $0-1$ & 0.565 \\
\hline Area $D \neq$ & & & 0.80 & $0.2-1$ & & & 0.60 & $0-1$ & 0.340 \\
\hline
\end{tabular}

The NoCC, NoCI, areas $\mathrm{B}, \mathrm{C}$, and $\mathrm{D}$ in the education group and the NoCC, NoCI, and areas $\mathrm{A}$ and $\mathrm{C}$ in the control group were improved at four weeks compared to baseline. The improvement in the $\mathrm{NoCC}, \mathrm{NoCl}$, and area $\mathrm{C}$ in the education group and in the NoCC, NoCI, and areas $\mathrm{A}$ and $\mathrm{C}$ in the control group were maintained at six months. Although a deterioration in the NoCC

Table 2. The differences between three occasions in outcome measures (Friedman test)

\begin{tabular}{|c|c|c|c|c|c|c|c|c|c|c|c|c|c|c|}
\hline & \multicolumn{6}{|c|}{ Education group $(n=27)$} & \multirow[b]{3}{*}{$p$} & \multicolumn{6}{|c|}{ Control group $(n=29)$} & \multirow[b]{3}{*}{$p$} \\
\hline & \multicolumn{2}{|c|}{ Baseline } & \multicolumn{2}{|c|}{$4^{\text {th }}$ week } & \multicolumn{2}{|c|}{$6^{\text {th }}$ month } & & \multicolumn{2}{|c|}{ Baseline } & \multicolumn{2}{|c|}{$4^{\text {th }}$ week } & \multicolumn{2}{|c|}{$6^{\text {th }}$ month } & \\
\hline & Median & Range & Median & Range & Median & Range & & Median & Range & Median & Range & Median & Range & \\
\hline NoCC & 16 & $9-23$ & 20 & $14-24$ & 19 & $12-24$ & 0.000 & 15 & $6-22$ & 18 & $10-23$ & 19 & $8-24$ & 0.003 \\
\hline $\mathrm{NoCl}$ & 6 & $2-11$ & 9 & $5-13$ & 8 & $4-13$ & 0.000 & 6 & $0-12$ & 8 & $3-12$ & 9 & $1-13$ & 0.000 \\
\hline Area A & 0.75 & $0.25-1$ & 0.75 & $0.38-1$ & 0.75 & $0.25-1$ & 0.477 & 0.62 & $0-1$ & 0.75 & $0.25-1$ & 0.87 & $0.13-1$ & 0.013 \\
\hline Area B & 0.33 & $0-0.67$ & 0.33 & $0-1$ & 0.33 & $0-1$ & 0.012 & 0.33 & $0-9.67$ & 0.33 & $0-0.67$ & 0.33 & $0-1$ & 0.193 \\
\hline Area C & 0.67 & $0.33-1$ & 0.89 & $0.67-1$ & 0.80 & 0.44-1 & 0.000 & 0.67 & $0-1$ & 0.78 & 0.33-1 & 0.89 & 0.44-1 & 0.013 \\
\hline Area D & 0.80 & $0.2-1$ & 1 & 0.33-1 & 0.80 & $0-1$ & 0.004 & 0.60 & $0-1$ & 0.80 & $0.2-1$ & 0.60 & $0.2-1$ & 0.103 \\
\hline
\end{tabular}


Table 3. Changes in level of patients' knowledge about disease (Wilcoxon signed rank test)

\begin{tabular}{|c|c|c|c|c|c|c|c|c|c|}
\hline & \multicolumn{2}{|c|}{ Baseline } & \multicolumn{2}{|c|}{$4^{\text {th }}$ week } & \multirow[b]{2}{*}{$p^{\mathrm{a}}$} & \multicolumn{2}{|c|}{$6^{\text {th }}$ month } & \multirow[b]{2}{*}{$p^{*}$} & \multirow[b]{2}{*}{$p^{* *}$} \\
\hline & Median & Range & Median & Range & & Median & Range & & \\
\hline \multicolumn{10}{|c|}{ Education group } \\
\hline $\mathrm{NoCC}$ & 16 & $9-23$ & 20 & $14-24$ & 0.000 & 19 & $12-24$ & $0.014^{b}$ & $0.002^{\mathrm{a}}$ \\
\hline $\mathrm{NoCI}$ & 6 & $2-11$ & 9 & $5-13$ & 0.000 & 8 & $4-13$ & 0.114 & $0.000^{\mathrm{a}}$ \\
\hline Area B & 0.33 & $0-0.67$ & 0.33 & $0-1$ & 0.031 & 0.33 & $0-1$ & 0.061 & 0.134 \\
\hline Area $\mathrm{C}$ & 0.67 & $0.33-1$ & 0.89 & $0.67-1$ & 0.000 & 0.80 & $0.44-1$ & $0.030^{\mathrm{b}}$ & $0.004^{\mathrm{a}}$ \\
\hline Area D & 0.80 & $0.2-1$ & 1 & $0.33-1$ & 0.001 & 0.80 & $0-1$ & $0.003^{b}$ & 0.648 \\
\hline \multicolumn{10}{|c|}{ Control group } \\
\hline NoCC & 15 & $6-22$ & 18 & $10-23$ & 0.001 & 19 & $8-24$ & 0.582 & 0.003 \\
\hline $\mathrm{NoCl}$ & 6 & $0-12$ & 8 & $3-12$ & 0.000 & 9 & $1-13$ & 0.662 & $0.004^{a}$ \\
\hline Area A & 0.62 & $0-1$ & 0.75 & $0.25-1$ & 0.004 & 0.87 & $0.13-1$ & 0.767 & $0.007^{a}$ \\
\hline Area $C$ & 0.67 & $0-1$ & 0.78 & $0.33-1$ & 0.007 & 0.89 & $0.44-1$ & 0.169 & $0.004^{\mathrm{a}}$ \\
\hline
\end{tabular}

Table 4. Comparisons between groups in respect to changes in variables (Mann-Whitney U test)

\begin{tabular}{|c|c|c|c|c|c|}
\hline & \multicolumn{2}{|c|}{ Education group } & \multicolumn{2}{|c|}{ Control group } & \multirow[b]{2}{*}{$p$} \\
\hline & Median & Range & Median & Range & \\
\hline \multicolumn{6}{|l|}{ Changes in NoCC } \\
\hline Baseline- $4^{\text {th }}$ week & -4 & -11 to 5 & -2 & -10 to 5 & 0.111 \\
\hline $4^{\text {th }}$ week- $6^{\text {th }}$ month & 1 & -4 to 6 & 0 & -4 to 4 & 0.035 \\
\hline Baseline- $6^{\text {th }}$ month & -2 & -9 to 6 & -3 & -14 to 7 & 0.915 \\
\hline \multicolumn{6}{|l|}{ Changes in $\mathrm{NoCI}$} \\
\hline Baseline- $4^{\text {th }}$ week & -3 & -8 to 4 & -2 & -7 to 2 & 0.502 \\
\hline $4^{\text {th }}$ week- $6^{\text {th }}$ month & 1 & -3 to 5 & 1 & -4 to 4 & 0.336 \\
\hline Baseline- $6^{\text {th }}$ month & -2 & -7 to 2 & -2 & -10 to 4 & 0.830 \\
\hline \multicolumn{6}{|l|}{ Changes in Area C } \\
\hline Baseline- $4^{\text {th }}$ week & -0.22 & -0.67 to 0.22 & 0 & -0.78 to 0.34 & 0.562 \\
\hline $4^{\text {th }}$ week- $6^{\text {th }}$ month & 0.11 & -0.22 to 0.34 & -0.11 & -0.29 to 0.23 & 0.012 \\
\hline Baseline- $6^{\text {th }}$ month & -0.11 & -0.45 to 0.44 & -0.11 & -0.89 to 0.12 & 0.791 \\
\hline
\end{tabular}

and area $\mathrm{C}$ scores in the education group was observed at six months compared to four-week scores, the NoCC, NoCI, and area $\mathrm{C}$ scores were improved in both groups at six months compared to baseline (Table 3).

\section{Inter-group analysis}

Inter-group analysis was performed to compare the groups with respect to change in scores. The only scores that improved in both groups were NoCC, NoCI, and area C. Therefore, 
the comparison was performed for only these variables. According to the analysis results, these deteriorations in the NoCC and area $\mathrm{C}$ at six months compared to four weeks led to a difference between the groups $(p=0.035$ for NoCC and 0.012 for area C) (Table 4). However, the changes in the NoCC, NoCI, and area $\mathrm{C}$ at six months compared to baseline were similar between the groups (Table 4).

\section{DISCUSSION}

The present study revealed that short-term improvement in the total knowledge scores (NoCC and NoCI) was maintained at six months in both groups. The NoCC represents correct choices and NoCI represents correct items. Also, the increase in area $\mathrm{C}$ score in both groups and the improvement in area $\mathrm{A}$ score in the control group were maintained over six months. This finding may be due to the fact that areas $A$ and $C$ cover the matters on which patients and physicians most discuss. Area $\mathrm{C}$ represents the drug treatment and physical therapy knowledge and area $\mathrm{A}$ is general knowledge area querying symptoms and blood tests. Claudepierre et al. ${ }^{6}$ reported that the knowledge was best in pharmacotherapy and physical therapy area in their study. The reason for this was attributed to the fact that most patients received physical therapy and heard about these topics from their healthcare professionals many times.

The only score which remained unchanged in both groups was area B, although a tendency toward the increase between the first two visits in the education group. Area $\mathrm{B}$ queries knowledge concerning immunogenetics. It may be concluded that patients did not pay much attention to this topic, as they were not at all interested in immunogenetics. Mazzuca ${ }^{22}$ reported that patients' priority was not to learn about pathophysiology of disease; instead, they needed to have information beneficial for coping with problems concerning daily routine. For patients with spondyloarthritis, education including some key knowledge such as managing pain and fatigue, disease flares and adaptive skills, which are more useful and interesting for patients, is recommended. ${ }^{16}$

Although an improvement between the first and final visits, there was some deterioration in few scores (NoCC, areas C and D) from the second to the third visit in the education group. In a study conducted by Riemsma et al., ${ }^{17}$ a decrease in the RA patients' knowledge after an educational activity was reported with amazement in both experimental and control groups. Taal et al. ${ }^{4}$ also suggested that short-term gain derived from the patient education often disappeared gradually over time. Likewise, in our study, the increase in area $\mathrm{D}$ (joint protection, pacing, and priorities area) was not maintained at six months. In their study, Claudepierre et al. ${ }^{6}$ specified the area $\mathrm{D}$ requiring special attention in educational programs due to poor baseline knowledge in this domain. Also, several authors reported the use of exercise, joint protection, and energy conservation as the least-known topics. ${ }^{23-25}$

An effective patient education is expected to increase the knowledge and make patients successful in coping, problem-solving, and rightly exercising. ${ }^{4}$ On the other hand, the topics that patients demand and need to learn more about have been addressed by several studies. In a study, daily living, disease process, and diagnostic procedures were reported as educational needs for RA patients. ${ }^{26}$ Self-care of fatigue and adaptive skills were the key knowledges for RA and spondyloarthritis patients in the study of Beauvais et al. ${ }^{16}$ It should be noted that, despite the aforementioned needs, these areas are not always the most learned ones. ${ }^{27}$ Likewise, in our study, area D score was not increased in the booklet group. Although it was improved in the education group soon after educational sessions ended, this improvement was not maintained over six months. This finding is consistent with another study, indicating a transient benefit of education in patients with RA. ${ }^{28}$ Besides, the association between learning and behavior change was frequently reported as weak or not apparent. ${ }^{18,20,28-30}$ However, this issue was not evaluated in our study.

Male AS patients have been supposed as not willing to obtain further information than they already have. ${ }^{31}$ No knowledge gain for some domains, even in the education group, may be due to the male predominance in our sample. In addition, in previous studies, patient education programs tailored to particular needs and demands of an individual have been recommended. ${ }^{1,7,17,18,26}$ The content of educational 
interventions in our study was not established by considering what participants needed to know. Also, it was reported that AS patients preferred to be informed by their physicians through face-to-face, individualized interviews, rather than group education providing generic information about AS. ${ }^{31}$ Similarly, Warsi et al. ${ }^{32}$ showed the superiority of face-to-face education to group activities for arthritis patients. In contrast, Riemsma et al. ${ }^{17}$ reported no effects of individual education on knowledge for patients with RA and underlined the cruciality of patient education tailored to patients' need and problems. Taken together, in order to obtain a result indicating superiority of any method to booklet alone, patients' opinions should be addressed while developing both the method and content of educational programs.

In the literature, there are data suggesting that patients with AS are provided more information and instruction from internet search and during medical care than patients with other types of inflammatory arthritis. In a study, patients' demands were prioritized relating to the information about new treatment alternatives, rather than complications and prognosis. ${ }^{31}$ Also, the patients noted their complaints about negative tone of the information style. There may be a similar negative influence in our study; however, it was not feasible to control the manner of transferring knowledge.

The participants in our study were dropped out from the study in case of non-attendance for even one session. The non-attendance rates of $32.5 \%$ for the education group and $27.5 \%$ for the control group are acceptable, while comparing to the other studies. The only study assessing the improvement of AS patients' knowledge after educational support group participation reported a completion rate of $27 \% .^{20}$ Lorig et al. ${ }^{33}$ also found $70 \%$ completion in their study including mixed-arthritis group. In our study, the primary reason for non-attendance in both education and control groups (four participants in each) was inability to get permission from the work. This is not surprising, considering the relatively low mean age of participants who are in the active working age group. In addition, interference to family responsibilities and difficulty in transportation problems are the other obstacles that participants faced.
The effects of education in our study were evaluated using experimental and control groups, pre-intervention, and post-intervention measurements, and re-assessing after a period of not less than six months, as recommended. ${ }^{4}$ The booklet that we used led to gain in knowledge, while peer-led education did not provide an additional gain. Similarly, booklet alone was as successful as booklet with mind map in a study assessing the effectiveness of booklet with or without a mind map on RA patients' knowledge. ${ }^{9}$ In the present study, we intended particularly to compare the effectiveness of reading a booklet alone or booklet + peer-led group education and, therefore, we paid attention to create a booklet and educational program which were of the same content.

There are some limitations and strengths of our study. Although they are comparable to that of previous studies as discussed above, the small sample size and dropout rate are the main limitations. The change in the exercise habits and healthcare use (frequency of specialist visits) were unable to be assessed. It is reasonable to measure these variables in further studies. However, it is worthy to note that, according to a Cochrane review, lay-led self-management education programs have no influence on the frequency of physician visits or amount of healthcare resource use. ${ }^{15}$ It has been suggested that educational programs should focus on the areas in which patient knowledge is deficient and on the patients that are most likely to benefit from education. ${ }^{6}$ In our study, we did not interview with patients to identify these details at the beginning of the study.

One of the main strengths of our study is its ability to provide information about knowledge gain, not in totally, but also in specific topics. Secondly, attendance was an important issue in our study and missing even a single session was accepted as a reason for dropout. Besides, six-month follow-up period is not below the recommended minimum length of duration. ${ }^{4,15}$

In conclusion, a considerable amount of knowledge transfer was achieved by reading a booklet alone and to participate in a peer-led education group did not add more in this study. The knowledge gain in both groups may indicate the information gap to be filled even for patients with AS, assuming a patient population as having 
substantial knowledge about their disease. It appears that patients' interest mainly focuses on drug treatment and physical therapy, due to a higher gain in this topic. We can infer from this finding that education tailored to patients' needs is worth trying. By providing a face-to-face interview, the content of our educational activity would be promising for knowledge enhancement than booklet alone. However, due to the novel coronavirus 2019 (COVID-19) pandemic, communication between patients and healthcare professionals in the clinical settings has been disrupted. Currently, tele-medicine has become an option. This type of approach may improve access to care and can be an effective tool to provide education. Healthcare professionals may benefit from technological possibilities to carry out further studies in this field.

\section{Declaration of conflicting interests}

The authors declared no conflicts of interest with respect to the authorship and/or publication of this article.

\section{Funding}

The authors received no financial support for the research and/or authorship of this article.

\section{REFERENCES}

1. Lorig K, Visser A. Arthritis patient education standards: A model for the future. Patient Educ Couns 1994:24:3-7.

2. Kääriäinen $M$, Kukkurainen $M L$, Kyngäs $H$, Karppinen L. Improving the quality of rheumatoid arthritis patients' education using written information. Musculoskeletal Care 2011;9:19-24.

3. Tucker M, Kirwan JR. Does patient education in rheumatoid arthritis have therapeutic potential? Ann Rheum Dis 1991;50 Suppl 3:422-8.

4. Taal E, Rasker JJ, Wiegman O. Group education for rheumatoid arthritis patients. Semin Arthritis Rheum 1997;26:805-16.

5. Lubrano E, Helliwell $P$, Moreno P, Griffiths B, Emery P, Veale D. The assessment of knowledge in ankylosing spondylitis patients by a self-administered questionnaire. Br J Rheumatol 1998;37:437-41.

6. Claudepierre P, Flipo RM, Sibilia J, Berthelot JM, Goupille P, Cortinovis S, et al. Patient knowledge of their disease: A French multicenter study in ankylosing spondylitis. Joint Bone Spine 2004;71:550-6.

7. Zangi HA, Ndosi M, Adams J, Andersen L, Bode C, Boström C, et al. EULAR recommendations for patient education for people with inflammatory arthritis. Ann Rheum Dis 2015;74:954-62.
8. Ramos-Remus C, Salcedo-Rocha AL, Prieto-Parra RE, Galvan-Villegas F. How important is patient education? Baillieres Best Pract Res Clin Rheumatol 2000;14:689-703.

9. Maggs FM, Jubb RW, Kemm JR. Single-blind randomized controlled trial of an educational booklet for patients with chronic arthritis. $\mathrm{Br} \mathrm{J}$ Rheumatol 1996;35:775-7.

10. Barlow JH, Wright CC. Knowledge in patients with rheumatoid arthritis: A longer term follow-up of a randomized controlled study of patient education leaflets. Br J Rheumatol 1998;37:373-6.

11. Walker D, Adebajo A, Heslop P, Hill J, Firth J, Bishop P, et al. Patient education in rheumatoid arthritis: The effectiveness of the ARC booklet and the mind map. Rheumatology (Oxford) 2007;46:1593-6.

12. Riemsma RP, Taal E, Rasker JJ. Group education for patients with rheumatoid arthritis and their partners. Arthritis Rheum 2003;49:556-66.

13. Barlow JH, Barefoot J. Group education for people with arthritis. Patient Educ Couns 1996;27:257-67.

14. Warsi A, LaValley MP, Wang PS, Avorn J, Solomon $\mathrm{DH}$. Arthritis self-management education programs: A meta-analysis of the effect on pain and disability. Arthritis Rheum 2003;48:2207-13.

15. Lewin SA, Dick J, Pond P, Zwarenstein M, Aja G, van Wyk B, et al. Lay health workers in primary and community health care. Cochrane Database Syst Rev 2005;(1):CD004015.

16. Beauvais $C$, Rodère $M$, Pereira B, Legoupil N, Piperno M, Pallot Prades B, et al. Essential knowledge for patients with rheumatoid arthritis or spondyloarthritis: Results of a multicentric survey in France among health professionals and patients. Joint Bone Spine 2019;86:747-52.

17. Riemsma RP, Taal E, Brus HL, Rasker JJ, Wiegman O. Coordinated individual education with an arthritis passport for patients with rheumatoid arthritis. Arthritis Care Res 1997;10:238-49.

18. Lindroth Y, Bauman A, Barnes C, McCredie M, Brooks PM. A controlled evaluation of arthritis education. Br J Rheumatol 1989;28:7-12.

19. Riemsma RP, Kirwan JR, Taal E, Rasker JJ. Patient education for adults with rheumatoid arthritis. Cochrane Database Syst Rev 2003;(2):CD003688.

20. Gross M, Brandt KD. Educational support groups of patients with ankylosing spondylitis: A preliminary report. Patient Couns Health Educ 1981;3:6-12.

21. Kaya T, Goksel Karatepe A, Atici Ozturk P, Gunaydin $R$. Impact of peer-led group education on the quality of life in patients with ankylosing spondylitis. Int $\mathrm{J}$ Rheum Dis 2016;19:184-91.

22. Mazzuca SA. Does patient education in chronic disease have therapeutic value? J Chronic Dis 1982;35:521-9.

23. Kamruzzaman AKM, Chowdhury MR, Islam MN, Sultan I, Ahmed S, Shahin A, et al. The knowledge 
level of rheumatoid arthritis patients about their disease in a developing country. A study in 168 Bangladeshi RA patients. Clin Rheumatol 2020;39:1315-23.

24. Barlow JH, Cullen LA, Rowe IF. Comparison of knowledge and psychological well-being between patients with a short disease duration $(<$ or $=1$ year) and patients with more established rheumatoid arthritis ( $>$ or $=10$ years duration). Patient Educ Couns 1999;38:195-203.

25. Hill J, Bird HA, Hopkins R, Lawton C, Wright V. The development and use of Patient Knowledge Questionnaire in rheumatoid arthritis. Br J Rheumatol 1991;30:45-9.

26. Silvers IJ, Hovell MF, Weisman MH, Mueller MR. Assessing physician/patient perceptions in rheumatoid arthritis. A vital component in patient education. Arthritis Rheum 1985;28:300-7.

27. Lorish C, Parker J, Wade K, Brown S. Rheumatoid arthritis patients' knowledge of their disease and treatment: a survey of hospitalized patients. Arthritis Rheum 1983;(Suppl)26:S82.
28. Potts M, Brandt KD. Analysis of education-support groups for patients with rheumatoid arthritis. Patient Couns Health Educ 1983;4:161-6.

29. Lorig K, Konkol L, Gonzalez V. Arthritis patient education: A review of the literature. Patient Educ Couns 1987; 10:207-52.

30. Cohen JL, Sauter SV, deVellis RF, deVellis BM. Evaluation of arthritis self-management courses led by laypersons and by professionals. Arthritis Rheum. 1986;29:388-93.

31. Cooksey R, Brophy S, Husain MJ, Irvine E, Davies H, Siebert $\mathrm{S}$. The information needs of people living with ankylosing spondylitis: A questionnaire survey. BMC Musculoskelet Disord 2012;13:243.

32. Warsi A, Wang PS, LaValley MP, Avorn J, Solomon $\mathrm{DH}$. Self-management education programs in chronic disease: A systematic review and methodological critique of the literature. Arch Intern Med 2004;164:1641-9.

33. Lorig K, Feigenbaum P, Regan C, Ung E, Chastain RL, Holman HR. A comparison of lay-taught and professional-taught arthritis self-management courses. J Rheumatol 1986;13:763-7. 